Article

\title{
Synthesis and Characterization of $\left(\mathrm{pyNO}^{-}\right)_{2} \mathrm{GaCl}$ : A Redox-Active Gallium Complex
}

\author{
Jacob M. Kirsh ${ }^{1}$, Audra J. Woodside ${ }^{1}$, Brian C. Manor ${ }^{2}$, Patrick J. Carroll ${ }^{2}$, Paul R. Rablen ${ }^{1}$ and \\ Christopher R. Graves $1, *$ (1)
}

1 Department of Chemistry \& Biochemistry, Swarthmore College, 500 College Avenue, Swarthmore, PA 19081, USA; Jkirsh@stanford.edu (J.M.K.); awoodsi1@swarthmore.edu (A.J.W.); prablen1@swarthmore.edu (P.R.R.)

2 Department of Chemistry, University of Pennsylvania, 231 South 34th Street, Philadelphia, PA 19104, USA; bmanor@sas.upenn.edu (B.C.M.); carrollp@sas.upenn.edu (P.J.C.)

* Correspondence: cgraves1@swarthmore.edu; Tel.: +1-610-690-4882

Received: 14 April 2018; Accepted: 15 May 2018; Published: 21 May 2018

\begin{abstract}
We report the synthesis of a gallium complex incorporating redox-active pyridyl nitroxide ligands. The $\left(\mathrm{pyNO}^{-}\right)_{2} \mathrm{GaCl}$ complex was prepared in $85 \%$ yield via a salt metathesis route and was characterized by ${ }^{1} \mathrm{H}$ and ${ }^{13} \mathrm{C}$ NMR spectroscopies, $\mathrm{X}$-ray diffraction, and theory. UV-Vis absorption spectroscopy and electrochemistry were used to access the optical and electrochemical properties of the complex, respectively. Our discussion focuses primarily on a comparison of the gallium complex to the corresponding aluminum derivative and shows that although the complexes are very similar, small differences in the electronic structure of the complexes can be correlated to the identity of the metal.
\end{abstract}

Keywords: gallium; redox-active ligand; non-innocent ligand; Lewis acid; Group 13 metals

\section{Introduction}

The synthesis of metal complexes of redox-active and non-innocent ligands is a research area that has been expanding in recent years and has resulted in new classes of complexes for metals from throughout the periodic table [1-4]. Of specific interest to us is the ability to modulate the reactivity of redox-active ligands through coordination of Lewis acids. We are specifically interested in how coordination of Lewis acids with different stabilizing effects change the electronic structure of a common redox-active ligand. In this vein, we have been interested in the development of aluminum complexes of redox active-ligands [5-9] and have recently reported the synthesis and characterization of a series of Al-nitroxide complexes [7,8]. The nitroxide functional group is well known to exist over three oxidation states: the reduced aminoxyl anion $\left(\mathrm{R}_{2} \mathrm{~N}-\mathrm{O}^{-}\right)$, the neutral radical $\left(\mathrm{R}_{2} \mathrm{~N}-\mathrm{O}^{\bullet}\right)$, and the oxidized oxoammonium cation $\left(\mathrm{R}_{2} \mathrm{~N}=\mathrm{O}^{+}\right)$(Figure 1 ).
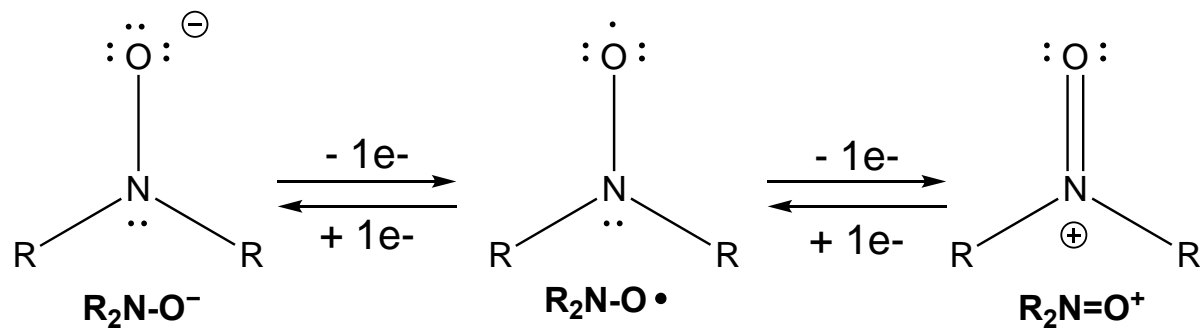

Figure 1. The nitroxide functional group across three oxidation states. 
The Schelter group has reported the synthetic chemistry for a series of pyridyl-hydroxylamines $\left({ }^{\mathrm{R}}\right.$ pyNOH$)$ and demonstrated their redox activities [10]. Metal complexes of these ligands have been prepared for several f-block [11-15] and transition [16-18] metals. Inspired by these compounds we prepared and fully characterized aluminum complexes of the type $\left({ }^{\mathrm{R}} \mathrm{pyNO}^{-}\right)_{2} \mathrm{AlCl}\left({ }^{\mathrm{R}} \mathrm{pyNO} \mathrm{N}^{-}=\right.$ $N$-tert-butyl- $N$-(2-(5-R-pyridyl))nitroxyl, $\left.\mathrm{R}=\mathrm{H}, \mathrm{CH}_{3}, \mathrm{CF}_{3}\right)[7]$ and $\left\{\left(\mu^{-}{ }^{\mathrm{R}} \mathrm{pyNO}^{-}\right) \mathrm{Al}\left(\mathrm{CH}_{3}\right)_{2}\right\}_{2}(\mathrm{R}=\mathrm{H}$, $\mathrm{CH}_{3}$ ) [8] and explored their electrochemical behavior. The results of this study suggested that coordination to the Lewis-acidic aluminum ion affected the redox energetics of the ligand to stabilize the reduced $\mathrm{pyNO}^{-}$form. In their work with iminopyridine ligands, the Berben group demonstrated key differences in the electrochemical behavior of the aluminum versus gallium $\left[\left(\mathrm{IP}^{2-}\right)_{2} \mathrm{M}\right]^{-}$anion $(\mathrm{M}=\mathrm{Al}$ or $\mathrm{Ga}$ ) which translated to different reaction profiles for the two complexes [19-21]. In light of these results, we have become interested in the preparation of redox-active ligand complexes of other group 13 metals, namely gallium and indium, to access how the identity of the metal translates to differences in the physical properties of the complexes. In this current contribution, we report the synthesis of the pyridyl-nitroxide gallium complex $\left(\mathrm{pyNO}^{-}\right)_{2} \mathrm{GaCl}$ and present its characterization by various physical methods. We then discuss the results in the context of the corresponding aluminum complex.

\section{Results}

\subsection{Synthesis and Spectroscopic Characterization}

Our synthetic strategy is outlined in Scheme 1: Reaction of N-tert-butyl-N-(2-pyridyl) hydroxylamine (pyNOH) with an equimolar amount of $\mathrm{NaN}\left(\mathrm{SiMe}_{3}\right)_{2}$ in tetrahydrofuran (THF) followed by addition of 0.5 equiv of $\mathrm{GaCl}_{3}$ gave the $\left(\mathrm{pyNO}^{-}\right)_{2} \mathrm{GaCl}(\mathbf{1})$ complex in $85 \%$ yield. The compound was isolated as a yellow solid that is indefinitely stable in the solid state when stored in the freezer $\left(-25^{\circ} \mathrm{C}\right)$ under an $\mathrm{N}_{2}$ environment. We also attempted the synthesis of the corresponding indium complex under identical reaction conditions. However, unlike the aluminum and gallium systems which cleanly provide monometallic complexes, there is a ligand redistribution in the indium compound and after crystallization the zwitterionic $\left[\left(\mathrm{pyNO}^{-}\right)_{2} \mathrm{In}\right]\left[\left(\mathrm{pyNO}^{-}\right)_{2} \mathrm{InCl}_{2}\right](2)$ complex is isolated. Compound 2 was crystalized from slow diffusion of pentane into a concentrated THF solution at $-25^{\circ} \mathrm{C}$, and it is not clear if the crystal sample obtained is representative of the bulk sample. In this work, we are primarily interested in comparing the analogous $\left(\mathrm{pyNO}^{-}\right)_{2} \mathrm{MCl}$ complexes, and further characterization of complex 2 beyond X-ray was not carried out. A representation of the solid-state structure of 2 along with selected bonding metrics is provided in the Supplementary Materials.

The $\left(\mathrm{pyNO}^{-}\right)_{2} \mathrm{GaCl}$ complex was readily characterized by ${ }^{1} \mathrm{H}$ and ${ }^{13} \mathrm{C}$ NMR spectroscopies, which support assignment of the structure as diamagnetic with a $\mathrm{Ga}^{3+}$ cation coordinated by fully reduced nitroxide ligands. As expected, the ${ }^{1} \mathrm{H}$ NMR spectrum of the complex lacks the $\mathrm{O}-\mathrm{H}$ signal of the ligand precursor but has all of the remaining ligand signatures that are readily assignable and in the expected chemical ranges. There is single resonance attributable to the $t$-Bu protons, which appears as a singlet which integrates to $18 \mathrm{H}$, along with four unique aromatic resonances each of which integrates to $2 \mathrm{H}$. All four of the aromatic signals exhibits a doublet-of-doublet-of-doublet coupling pattern indicative of coupling between all four of the protons within the aromatic ring. Site assignments for the pyridyl hydrogens are given in the Supporting Information. The ${ }^{13} \mathrm{C}$ NMR spectra of $\mathbf{1}$ has characteristic signals for the $t$-Bu groups (resonances at $28.3 \mathrm{ppm}\left(\mathrm{C}\left(\mathrm{CH}_{3}\right)_{3}\right)$ and $61.7 \mathrm{ppm}\left(\mathrm{C}\left(\mathrm{CH}_{3}\right)_{3}\right)$ along with five aromatic signals. The single set of ligand-based resonances in both the ${ }^{1} \mathrm{H}$ and ${ }^{13} \mathrm{C}$ NMR spectra indicate symmetry equivalent $\mathrm{pyNO}^{-}$ligands in the complex. 


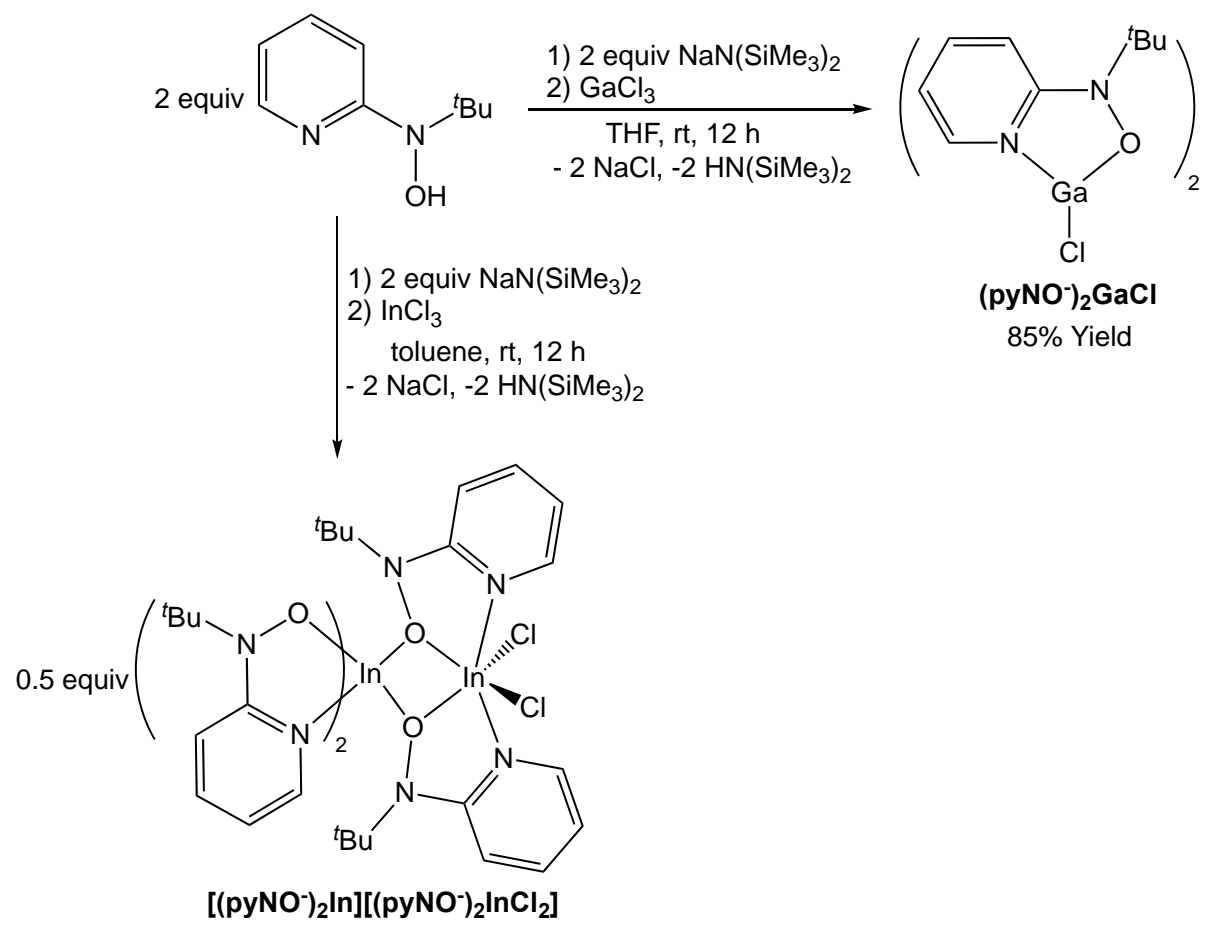

Scheme 1. Synthesis of the gallium pyridyl nitroxide complex $\left(\mathrm{pyNO}^{-}\right)_{2} \mathrm{GaCl}(\mathbf{1})$ and the indium dimer $\left[\left(\mathrm{pyNO}^{-}\right)_{2} \mathrm{In}\right]\left[\left(\mathrm{pyNO}^{-}\right)_{2} \mathrm{InCl}_{2}\right](2)$.

\subsection{Structural Characterization}

Single crystals of the $\left(\mathrm{pyNO}^{-}\right)_{2} \mathrm{GaCl}$ complex were grown from a concentrated solution of diethyl ether at $-25^{\circ} \mathrm{C}$. The molecule crystallizes in the orthorhombic space group Pna2 ${ }_{1}$ and collected data refined to a final R1 value of 0.0226. A representation of the molecule is shown in Figure 2 and selected bonding metrics are provided in Table 1.

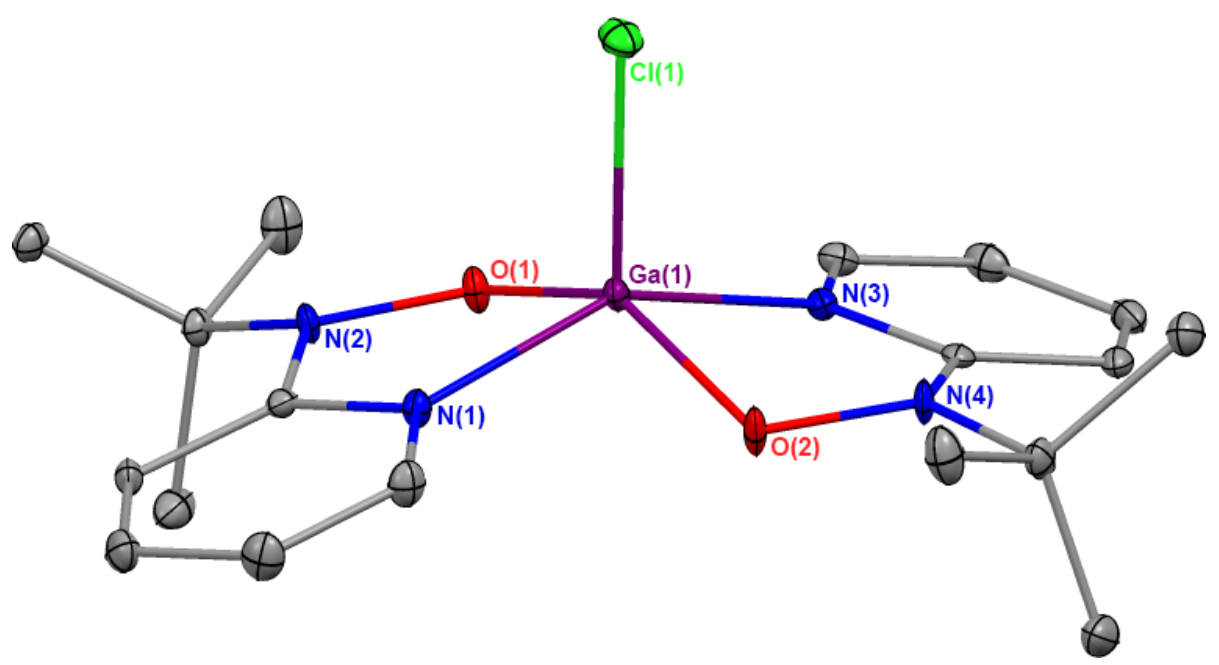

Figure 2. Solid state structure of $\left(\mathrm{pyNO}^{-}\right)_{2} \mathrm{GaCl}(\mathbf{1})$. Ellipsoids are projected at $30 \%$ probability and $\mathrm{H}$ atoms are omitted for clarity. 
Table 1. Selected bond distances $(\AA)$ and angles $\left({ }^{\circ}\right)$ the $\left(\mathrm{pyNO}^{-}\right)_{2} \mathrm{GaCl}$ complex obtained from the solid-state structure and theoretical analysis.

\begin{tabular}{ccc}
\hline & Solid-State & Theoretical \\
\hline $\mathrm{Ga}(1)-\mathrm{Cl}(1)$ & $2.2215(7)$ & 2.2918 \\
\hline $\mathrm{Ga}(1)-\mathrm{O}(1)$ & $1.8890(18)$ & 1.8936 \\
$\mathrm{Ga}(1)-\mathrm{O}(2)$ & $1.9011(18)$ & 2.0028 \\
\hline $\mathrm{Ga}(1)-\mathrm{N}(1)$ & $1.991(2)$ & \\
$\mathrm{Ga}(1)-\mathrm{N}(3)$ & $2.006(2)$ & 1.4265 \\
\hline $\mathrm{N}(2)-\mathrm{O}(1)$ & $1.397(3)$ & \\
$\mathrm{N}(4)-\mathrm{O}(2)$ & $1.397(3)$ & \\
\hline $\mathrm{O}(1)-\mathrm{Ga}(1)-\mathrm{N}(1)$ & $81.00(8)$ & \\
$\mathrm{O}(1)-\mathrm{Ga}(1)-\mathrm{N}(3)$ & $91.61(8)$ & 138.53 \\
$\mathrm{O}(2)-\mathrm{Ga}(1)-\mathrm{N}(1)$ & $88.87(8)$ & 155.45 \\
$\mathrm{O}(2)-\mathrm{Ga}(1)-\mathrm{N}(3)$ & $80.28(8)$ & 110.74 \\
\hline $\mathrm{O}(1)-\mathrm{Ga}(1)-\mathrm{O}(2)$ & $145.14(8)$ & \\
\hline $\mathrm{N}(1)-\mathrm{Ga}(1)-\mathrm{N}(3)$ & $149.25(9)$ & 102.28 \\
\hline $\mathrm{O}(1)-\mathrm{Ga}(1)-\mathrm{Cl}(1)$ & $108.00(6)$ & \\
$\mathrm{O}(2)-\mathrm{Ga}(1)-\mathrm{Cl}(1)$ & $106.86(6)$ & \\
\hline $\mathrm{N}(1)-\mathrm{Ga}(1)-\mathrm{Cl}(1)$ & $106.23(6)$ & \\
$\mathrm{N}(3)-\mathrm{Ga}(1)-\mathrm{Cl}(1)$ & $104.44(6)$ & \\
\hline
\end{tabular}

Complex $\mathbf{1}$ is five-coordinate at the gallium cation with a $\tau_{5}$ value [22] of 0.07 and is best described as slightly distorted square pyramidal. The two pyridyl nitroxide ligands are $\mathrm{N}_{p y}, \mathrm{O}$-bound in a bidentate fashion and are arranged in the basal plane. The arrangement of the ligands results in the $\mathrm{O}-\mathrm{Al}-\mathrm{O}$ and $\mathrm{N}-\mathrm{Al}-\mathrm{N}$ atoms being in mutually trans arrangements, giving the complexes near $\mathrm{C}_{2}$ symmetry and supporting the equivalent ligands observed in the ${ }^{1} \mathrm{H}$ and ${ }^{13} \mathrm{C}$ NMR spectra. A chloride ligand completes the coordination sphere. The $\mathrm{Ga}-\mathrm{Cl}$ bond is in the range of other non-bridging $\mathrm{Ga}-\mathrm{Cl}$ bonds reported for structurally characterized five-coordinate gallium(III) complexes. For example, the bis(o-iminosemiquinonate) gallium(III) chloride complex reported by Piskunov et al. has a $\mathrm{Ga}-\mathrm{Cl}$ of 2.1875(5) $\AA$ [23] and the gallium salen complex reported by the Dagorne group has a Ga-Cl distance of 2.2255(6) $\AA$ [24] The bis( $\beta$-ketoiminate) gallium(III) chloride complex prepared by the Carmalt group has a $\mathrm{Ga}-\mathrm{Cl}$ bond length of distance 2.231(7) $\AA$ [25]. The $\mathrm{Ga}-\mathrm{N}_{\text {py }}$ bond distances are also similar to other $\mathrm{Ga}-\mathrm{N}$ distances reported for gallium complexes supporting pyridine ligands: The pyGaX $(\mathrm{X}=\mathrm{Cl}$ and $\mathrm{Br})$ complexes have an average $\mathrm{Ga}-\mathrm{N}$ distance of $1.98 \AA$ [26] while the $\left\{\mathrm{pyGaCl}_{2} \mathrm{H}\right\}_{2}$ dimer has Ga-N distances of 2.000(2) and 1.998(2) $\AA$ [27]. Several gallium complexes incorporating hydroxyl amine ligands have been structurally characterized, and the $\mathrm{Ga}-\mathrm{O}$ and $\mathrm{N}-\mathrm{O}$ distances observed for 1 compare well to their metrics. As representative examples, the $\mathrm{Ga}-\mathrm{O}$ bond length in the $\left(\mathrm{Me}_{2} \mathrm{GaONMe}_{2}\right)_{2}$ complex is 1.886(2) $\AA$ and the $\mathrm{N}-\mathrm{O}$ distance was 1.435(3) $\AA$ [28] while the analogous distances in the $\mathrm{GaH}_{2}$ (quinuclidine)(TEMPO) (TEMPO = tetramethylpiperidinyloxide) complex are 1.850(5) and 1.447(8) $\AA$, respectively [29]. Finally, the series of bis(hydroxylamine) gallium complexes prepared by the Mitzel group have an average Ga-O distance of $1.91 \AA$ and average $\mathrm{N}-\mathrm{O}$ distance of $1.44 \AA[30,31]$. In all cases, the $\mathrm{N}-\mathrm{O}$ bond distance in these complexes are longer than that observed for $\mathbf{1}$ (1.397(3) $\AA$ ). However, the $\mathrm{N}-\mathrm{O}$ bond distance in $\mathbf{1}$ does fit in the range of similar bonding parameters reported for metal complexes coordinated by the aminoxyl anion form of the pyridyl nitroxide ligand. For example, the cerium complexes $\left\{\mathrm{Ce}^{\mathrm{III}}\left(\mu{ }^{-}{ }^{\mathrm{R}} \mathrm{pyNO}^{-}\right)\left({ }^{\mathrm{R}} \mathrm{pyNO}^{-}\right)_{2}\right\}_{2}$ and $\mathrm{Ce}^{\mathrm{IV}}\left({ }^{\mathrm{R}} \mathrm{pyNO}^{-}\right)_{4}$ reported by the Schelter group have average $\mathrm{N}-\mathrm{O}$ distances of 1.37 and $1.38 \AA$ ), respectively $[12,13]$. The $\left[\mathrm{Cu}^{2+}\left(\mathrm{pyNO}^{-}\right)\left(\mathrm{pyNO}^{\bullet}\right)\right]^{+}$cation reported by the Ishida group has an $\mathrm{N}-\mathrm{O}$ distance for the pyNO ${ }^{-}$ligand in the range of 1.4092(8)-1.423(2) $\AA$ [18]. This complex also has neutral, radical pyNO ${ }^{\bullet}$ ligands which have N-O distances in the range of 1.298(3)-1.303(2) A. Similarly, the terbium complex $(\mathrm{hfac})_{3} \mathrm{~Tb}\left(\mathrm{pyNO}^{\bullet}\right)(\mathrm{Hhfac}=1,1,1,5,5,5$-hexafluoropentane-2,4-dione) has a $\mathrm{N}-\mathrm{O}$ 
distance of 1.279(9) $\AA$ [11] which is significantly shorter than the analogous distance observed for 1 . This supports the assignment of fully reduced $\mathrm{pyNO}^{-}$ligands in the gallium complex.

\subsection{Electronic Strucutre of the $\left(\mathrm{pyNO}^{-}\right)_{2} \mathrm{GaCl}$ Complex}

\subsubsection{Density Functional Theory (DFT) Studies}

The full geometry of the $\left(\mathrm{pyNO}^{-}\right)_{2} \mathrm{GaCl}$ complex was optimized using density functional theory with the molecule being constrained to $C_{2}$ symmetry. A representation of the optimized structure and a table of xyz coordinates are provided in the Supporting Information. Overall, the computed bond distances were found to be in good agreement with those obtained in the X-ray data (Table 1). With the exception of the $\mathrm{Ga}-\mathrm{Cl}$ distance, all of the computed bond distances centered around the gallium ion are within $0.05 \AA$. The $\mathrm{Ga}-\mathrm{Cl}$ in the computed structure is slightly longer by $\sim 0.07 \AA$. Similarly, all of the bond angles are also in good agreement, with the largest deviation being $\sim 6^{\circ}$ for the $\mathrm{O}-\mathrm{Ga}-\mathrm{O}$ and $\mathrm{N}-\mathrm{Ga}-\mathrm{N}$ angles. The charge distribution of the $\left(\mathrm{pyNO}^{-}\right)_{2} \mathrm{GaCl}$ complex was studied by the natural bonding orbital (NBO) method, with selected data given in Table 2. The gallium cation has a positive charge while the bonding heteroatoms and chloride have negative charges.

Table 2. Charge Distribution of the $\left(\mathrm{pyNO}^{-}\right)_{2} \mathrm{GaCl}$ Complex.

\begin{tabular}{cccc}
\hline $\mathrm{Ga}(1)$ & 1.124 & $\mathrm{Cl}(1)$ & -0.418 \\
$\mathrm{~N}(1) / \mathrm{N}(3)$ & -0.470 & $\mathrm{~N}(2) / \mathrm{N}(4)$ & -0.076 \\
$\mathrm{O}(1) / \mathrm{O}(2)$ & -0.565 & - & - \\
\hline
\end{tabular}

We also examined the molecular orbitals of the $\left(\mathrm{pyNO}^{-}\right)_{2} \mathrm{GaCl}$ complex. All of the frontier orbitals (Figure 3) are primarily localized on the $\mathrm{pyNO}^{-}$ligands. The $\mathrm{HOMO}$ and $\mathrm{HOMO}-1$ are similar in structure and energy (energy difference of $0.163 \mathrm{eV}$ ) and have electron density delocalized across the $\mathrm{N}-\mathrm{O}$ and pyridine groups of both $\mathrm{pyNO}^{-}$ligands, as well as some contribution from the chloride. The $\mathrm{HOMO}$ is antisymmetric with respect to $\mathrm{C}_{2}$ rotation about the $\mathrm{Ga}-\mathrm{Cl}$ bond while the HOMO-1 is symmetric about the same rotation. The LUMO and LUMO+1 are also similar in structure and also have a relationship relative to $\mathrm{C}_{2}$ rotation about the $\mathrm{Ga}-\mathrm{Cl}$ bond (the $\mathrm{LUMO}$ is symmetric to rotation and the $\mathrm{LUMO}+1$ is antisymmetric to rotation). The two virtual orbitals are degenerate (energy difference of $0.005 \mathrm{eV}$ ) and are localized primarily on the pyridine rings of the two pyNO ${ }^{-}$ligands with very little density on the $\mathrm{N}-\mathrm{O}$ fragment and none on the chloride ligand.

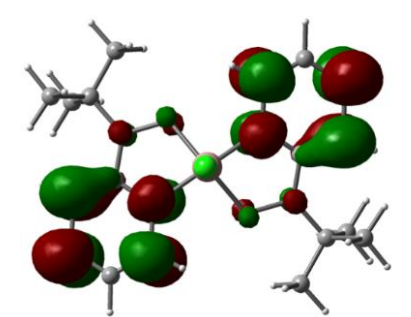

$\operatorname{LUMO}(-1.197 \mathrm{eV})$

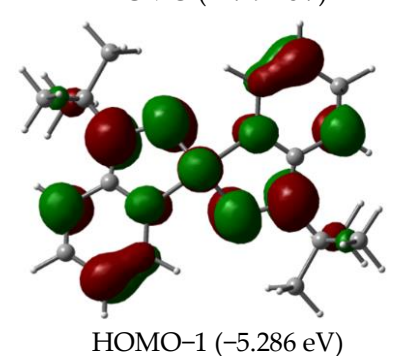

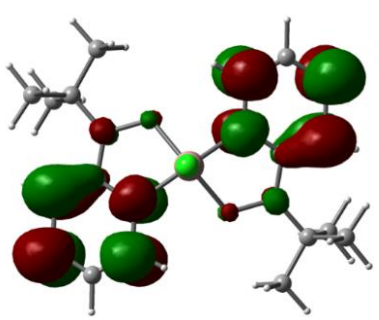

LUMO+1 (-1.192 eV)

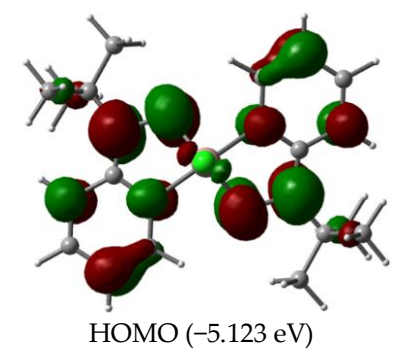

Figure 3. The frontier molecular orbitals of the $\left(\mathrm{pyNO}^{-}\right)_{2} \mathrm{GaCl}$ complex. The orbitals are visualized looking down the $\mathrm{Ga}-\mathrm{Cl}$ bond. 


\subsubsection{Absorption Spectra}

The absorption spectra of the $\left(\mathrm{pyNO}^{-}\right)_{2} \mathrm{GaCl}$ complex was collected in methylene chloride (Figure 4). The spectrum has a dominant feature at $281 \mathrm{~nm}\left(\varepsilon \sim 2300 \mathrm{M}^{-1} \cdot \mathrm{cm}^{-1}\right)$ and a smaller feature at $357 \mathrm{~nm}\left(\varepsilon \sim 550 \mathrm{M}^{-1} \cdot \mathrm{cm}^{-1}\right)$. We propose that both features result from primarily ligand based $\pi$-to- $\pi^{*}$ transitions, as was determined for the corresponding aluminum complex.

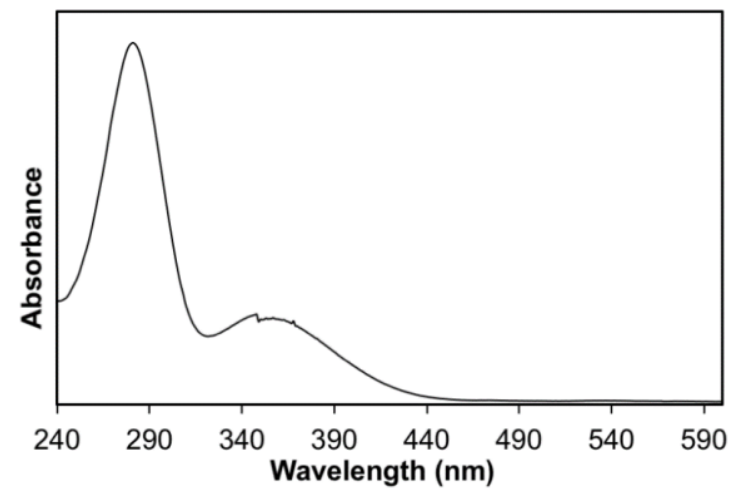

Figure 4. UV-Vis spectra of a $3.0 \times 10^{-4} \mathrm{M}$ solution of $\mathbf{1}$ in $\mathrm{CH}_{2} \mathrm{Cl}_{2}$.

\subsubsection{Electrochemistry}

The cyclic voltammogram of $\left(\mathrm{pyNO}^{-}\right)_{2} \mathrm{GaCl}$ was collected in $\mathrm{CH}_{2} \mathrm{Cl}_{2}$ and exhibits two features which we attribute to two sequential one-electron oxidation processes corresponding to the $\mathrm{N}-\mathrm{O}^{-} / \mathrm{N}-\mathrm{O}^{\bullet}$ couples of each pyNO $\mathrm{N}^{-}$ligand (Figure 5). We do not observe the other two oxidation processes corresponding to the $\mathrm{N}-\mathrm{O}^{\bullet} / \mathrm{N}=\mathrm{O}^{+}$couples in the electrochemical window. Coordination to the $\mathrm{Ga}^{3+}$ cation shifts the redox events to more positive potential relative to pyNOH [10], indicating that the Lewis acidic metal stabilizes the reduced aminoxyl anion $\mathrm{pyNO}^{-}$. For example, the first oxidation in 1 occurs at $0.24 \mathrm{~V}$ while the $\mathrm{pyNOH} / \mathrm{pyNO}^{0}$ couple for free ligand comes at $\mathrm{E}_{\frac{1}{2}}=-0.39 \mathrm{~V}$, for a shift in potential of $0.63 \mathrm{~V}$. All values are referenced to the ferrocene/ferrocenium couple. This is in line with chemistry reported by the Hayton group, who demonstrated that coordination of the TEMPO radical (TEMPO $=2,2,6,6$-tetramethylpiperidine- $N$-oxyl) to a Lewis acid significantly changes the reactivity of the molecule in the oxidation of various organic molecules.

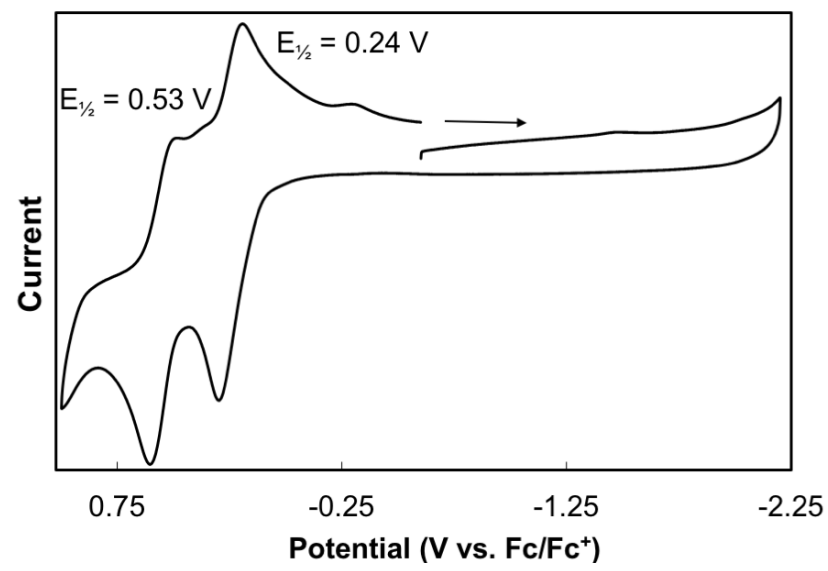

Figure 5. Cyclic voltammogram of 1 recorded in $0.1 \mathrm{M}\left[n-\mathrm{Pr}_{4} \mathrm{~N}\right]\left[\mathrm{BAr}^{\mathrm{F}}\right] \mathrm{CH}_{2} \mathrm{Cl}_{2}$ solution. 


\section{Discussion}

The $\left(\mathrm{pyNO}^{-}\right)_{2} \mathrm{GaCl}$ complex presented herein was prepared using a salt metathesis route analogous to that employed for the synthesis of our previously reported ( $\left.\mathrm{pyNO}^{-}\right)_{2} \mathrm{AlCl}$ complex. In both cases, complexes were isolated in high purity and yield. The gallium complex is significantly more soluble in hydrocarbon solvent relative to the aluminum complex, which reduced the recoverability of the former during recrystallization from hexane or pentane. The two complexes are isostructural, crystalizing as five-coordinate $\mathrm{M}^{3+}$ ions in distorted square pyramidal geometries. The gallium complex is closer to the idealized geometry as gauged by the $\tau_{5}$ geometry indices. Complex 1 has a $\tau_{5}$ value of 0.07 while the $\left(\mathrm{pyNO}^{-}\right)_{2} \mathrm{AlCl}$ complex has a $\tau_{5}$ value of 0.30 . The $\tau_{5}$ value for a square pyramid is 0 while that for a trigonal bipyramid is 1 [22]. Arrangement of the $\mathrm{pyNO}^{-}$ligands is also identical in the two complexes, with both ligands coordinating in the basal plane and with trans $\mathrm{O}-\mathrm{Al}-\mathrm{O}$ and $\mathrm{N}-\mathrm{Al}-\mathrm{N}$ geometries. The $\mathrm{Ga}-\mathrm{Cl}, \mathrm{Ga}-\mathrm{O}$, and $\mathrm{Ga}-\mathrm{N}$ distances in $\mathbf{1}$ are all slightly longer than the corresponding distance in the aluminum complex, as is expected given the larger ionic radius [32] and relative decrease in Lewis acidity [33] of the $\mathrm{Ga}^{3+}$ ion relative to the $\mathrm{Al}^{3+}$ ion.

The electronic structure of the $\left(\mathrm{pyNO}^{-}\right)_{2} \mathrm{MCl}$ complexes are also similar, with small differences being noted relative to the identity of the metal ion. The frontier molecular orbitals for the two complexes are essentially identical, although the HOMO-LUMO gap $(\Delta \mathrm{E}=3.926 \mathrm{eV})$ is slightly smaller for 1 relative to that for the aluminum complex $(\Delta \mathrm{E}=4.122 \mathrm{eV})$. The electronic transitions observed in the absorption spectra of the complexes are similar in shape, although there is a small red-shift (281 nm and $357 \mathrm{~nm}$ for 1 compared to $276 \mathrm{~nm}$ and $345 \mathrm{~nm}$ for $\left(\mathrm{pyNO}^{-}\right)_{2} \mathrm{AlCl}$ ) for both of the features in 1 relative to those of the aluminum complex. In both cases the transitions are primarily ligand based $\pi$-to- $\pi^{*}$, and it follows that the smaller HOMO-LUMO gap for $\mathbf{1}$ would result in lower energy transitions. The redox process observed for the gallium complex are much more reversible than they were for the aluminum complex. Additionally, the processes are shifted to more negative potentials relative to those observed for the aluminum by $\sim 0.1 \mathrm{~V}$. We propose this shift is due to the decreased Lewis acidity of $\mathrm{Ga}^{3+}$ relative to $\mathrm{Al}^{3+}$.

In this work, we have demonstrated that pyridyl nitroxide ligands can be coordinated to gallium to provide a new class of redox-active gallium complexes. Characterization of the complex shows similar physical and electronic structure to the aluminum analog, although there are systematic differences commensurate with the difference in Lewis acidity of the two metal ions. Although subtle, these results demonstrate the ability to tune the electronic nature of the redox-active ligand through judicial choice of Lewis-acid. Our future work will involve investigating the reaction chemistry of the $\left(\mathrm{pyNO}^{-}\right)_{2} \mathrm{GaCl}$ complex as well as the preparation of other gallium complexes supporting different classes of redox-active ligands.

\section{Materials and Methods}

\subsection{Physical Measurements}

The ${ }^{1} \mathrm{H}$ and ${ }^{13} \mathrm{C}$ NMR spectra were recorded at ambient temperature in $\mathrm{C}_{6} \mathrm{D}_{6}$ using a Bruker $400 \mathrm{MHz}$ spectrometer $\left(399.78 \mathrm{MHz}\right.$ for ${ }^{1} \mathrm{H}, 100.52 \mathrm{MHz}$ for ${ }^{13} \mathrm{C}$ ) (Bruker Corporation, Billerica, MA, USA). Chemical shifts were referenced to residual solvent. $\mathrm{s}=$ singlet, ad = apparent doublet, $\mathrm{ddd}=$ doublet of doublet of doublets. $\mathrm{CHN}$ analysis was performed on a crystalized sample of $\mathbf{1}$ at Midwest Microlab (Indianapolis, IN, USA). Electrochemical measurements were done in a glovebox under a dinitrogen environment using a $\mathrm{CHI}$ Potentiostat/Galvanostat (CH Instruments, Austin, TX, USA). A glassy carbon working electrode, a platinum wire auxiliary electrode, and a silver wire plated with $\mathrm{AgCl}$ as a quasi-reference electrode were utilized. Potentials were reported versus ferrocene, which was added as an internal standard for calibration at the end of each run. Solutions employed during these studies were $\sim 3 \mathrm{mM}$ in analyte and $100 \mathrm{mM}$ in $\left.\left[n-\mathrm{Pr}_{4} \mathrm{~N}\right]\left[\mathrm{BAr}{ }^{\mathrm{F}}\right]\left(\mathrm{BAr}_{\mathrm{F}}{ }^{-}=\mathrm{B}\left(3,5-\mathrm{CF}_{3}\right)_{2}-\mathrm{C}_{6} \mathrm{H}_{3}\right)_{4}{ }^{-}\right)$in $\sim 5 \mathrm{~mL}$ of $\mathrm{CH}_{2} \mathrm{Cl}_{2}$. All data were collected in a positive-feedback IR compensation mode at $500 \mathrm{mV} / \mathrm{s}$. The absorbance spectrum was collected using 
an Agilent Cary Series UV-Vis spectrophotometer (Agilent, Santa Clara, CA, USA) in anhydrous methylene chloride at ambient temperature and pressure.

\subsection{Preparation of Compounds}

All reactions and manipulations were performed under an inert atmosphere $\left(\mathrm{N}_{2}\right)$ using standard Schlenk techniques or in a Vacuum Atmospheres, Inc. NextGen drybox (Hawthorne, CA, USA) equipped with both oxygen and moisture purifier systems. Glassware was dried overnight at $150{ }^{\circ} \mathrm{C}$ before use. $\mathrm{C}_{6} \mathrm{D}_{6}$ was degassed and stored over $4 \AA$ molecular sieves prior to use. All solvents were sparged for 20 min with dry argon and dried using a commercial two-column solvent purification system comprising two columns packed with neutral alumina (for tetrahydrofuran, diethyl ether, acetonitrile, and dichloromethane) or Q5 reactant then neutral alumina (for hexanes). The ligand precursor $N$-tert-butyl-N-(2-pyridyl)hydroxylamine was prepared as reported by the Schelter group [10]. [n-Pr $4 \mathrm{~N}]\left[\mathrm{BAr}{ }^{\mathrm{F}}\right]$ was prepared according to literature procedure [34]. All other reagents were purchased from commercial sources and used as received.

Synthesis of $\left(\mathrm{pyNO}^{-}\right)_{2} \mathrm{GaCl}$ : N-tert-Butyl-N-(2-pyridyl)hydroxylamine $(0.50 \mathrm{~g}, 3.0 \mathrm{mmol})$ was added to a flask equipped with a magnetic stirbar and was dissolved in THF ( 25 mL). NaN $\left(\mathrm{SiMe}_{3}\right)_{2}$ $(0.62 \mathrm{~g}, 3.3 \mathrm{mmol})$ was added to the stirring solution in small portions over $0.5 \mathrm{~h}$. The resulting reaction mixture was stirred at room temperature for $4 \mathrm{~h}$ after which gallium trichloride $(0.26 \mathrm{~g}, 1.5 \mathrm{mmol})$ was added. The solution was stirred for $12 \mathrm{~h}$ at room temperature after which the reaction products were filtered over a Celite-padded frit and volatiles were removed from the filtrate. Crude product was dissolved in boiling hexanes $(\sim 25 \mathrm{~mL})$ and filtered over a celite-padded frit. Solvents were removed from the filtrate to give $\left(\mathrm{pyNO}^{-}\right)_{2} \mathrm{GaCl}$ as a yellow solid. Yield: $0.55 \mathrm{~g}, 1.3 \mathrm{mmol}(85 \%)$. ${ }^{1} \mathrm{H} \mathrm{NMR}$ $\left(\mathrm{C}_{6} \mathrm{D}_{6}\right): \delta 8.19(\mathrm{ddd}, J=5.8 \mathrm{~Hz}, J=1.6 \mathrm{~Hz}, J=0.9 \mathrm{~Hz}, 2 \mathrm{H}), 6.68(\mathrm{ddd}, J=9.2 \mathrm{~Hz}, J=6.8 \mathrm{~Hz}, J=1.8 \mathrm{~Hz}$, $2 \mathrm{H}), 6.46(\mathrm{ad}, J=9.2 \mathrm{~Hz}, 2 \mathrm{H}), 5.98(\mathrm{ddd}, J=6.8 \mathrm{~Hz}, J=5.9 \mathrm{~Hz}, J=0.7 \mathrm{~Hz}, 2 \mathrm{H}), 1.39(\mathrm{~s}, 18 \mathrm{H}) .{ }^{13} \mathrm{C}\left\{{ }^{1} \mathrm{H}\right\}$

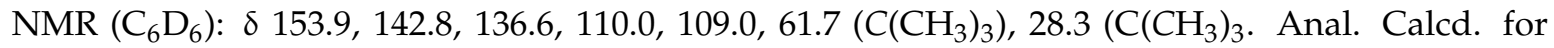
$\mathrm{C}_{18} \mathrm{H}_{26} \mathrm{ClGaN}_{4} \mathrm{O}_{2}$ : C, 49.63; H, 6.02; N, 12.86. Found: C, 49.78; H, 5.77; N, 12.58.

\subsection{X-ray Structure Determination}

X-ray diffraction data were collected either on a Bruker APEXII [35] CCD area detector (for 2) or a Bruker APEXIII [36] D8QUEST CMOS area detector (for 1) (Bruker Corporation, Billerica, MA, USA), both employing graphite-monochromated Mo-K $\alpha$ radiation $(\lambda=0.71073 \AA)$ at a temperature of $100 \mathrm{~K}$. Rotation frames were integrated using SAINT [37], producing a listing of unaveraged $\mathrm{F}^{2}$ and $\sigma\left(\mathrm{F}^{2}\right)$ values. The intensity data were corrected for Lorentz and polarization effects and for absorption using SADABS [38]. The structures were solved by direct methods (SHELXT [39]) and refined by full-matrix least squares based on $\mathrm{F}^{2}$ using SHELXL-2014 [40]. All non-hydrogen atoms were refined anisotropically and hydrogen atoms were refined using a riding model. CCDC 1833920-1833921 contain the supplementary crystallographic data for this paper. These data can be obtained free of charge via www.ccdc.cam.ac.uk/data_request/cif, or by emailing data_request@ccdc.cam.ac.uk, or by contacting The Cambridge Crystallographic Data Centre, 12 Union Road, Cambridge CB2 1EZ, UK; fax: $+44-1223-336033$.

$\left(p y \mathrm{NO}^{-}\right)_{2} \mathrm{GaCl}$ : Refinement converged to $\mathrm{R} 1=0.0226$ and $\mathrm{wR} 2=0.0481$ for 4230 observed reflections for which $F>4 \sigma(F)$ and $\mathrm{R} 1=0.0260$ and $\mathrm{wR} 2=0.0491$ and $\mathrm{GOF}=1.091$ for all 4528 unique, non-zero reflections and 241 variables.

$\left(p y \mathrm{NO}^{-}\right)_{2} \mathrm{In}\left(\mathrm{pyNO}^{-}\right)_{2} \mathrm{InCl}_{2}$ : Refinement converged to $\mathrm{R} 1=0.0253$ and $\mathrm{wR} 2=0.0574$ for 9724 observed reflections for which $F>4 \sigma(F)$ and $\mathrm{R} 1=0.0290$ and $\mathrm{wR} 2=0.0600$ and $\mathrm{GOF}=1.094$ for all 10,557 unique, non-zero reflections and 576 variables.

\subsection{Computational Details}

The structure optimization of $\left(\mathrm{pyNO}^{-}\right)_{2} \mathrm{GaCl}$ was performed with the Gaussian '09, Revision D.01 program using the B3LYP hybrid DFT method [41] and the LanL2DZ basis set [42-44]. Geometry 
optimization was performed using the crystal structure geometry as the initial starting point. Molecular orbitals are rendered at an isovalue of \pm 0.03 a.u. $\mathrm{NBO}$ analyses were performed using the NBO6 package [45].

Supplementary Materials: The following are available online at http:/ / www.mdpi.com/2304-6740/6/2/50/s1. Figures S1 and S2: ${ }^{1} \mathrm{H}$ NMR and ${ }^{13} \mathrm{C}$ NMR spectrum of $\left(\mathrm{pyNO}^{-}\right)_{2} \mathrm{GaCl}(\mathbf{1})$, Figure S3: Solid state structure of $\left\{\left(\text { pyNO }^{-}\right)_{2} \operatorname{In}\right\}\left\{\left(\text { pyNO }^{-}\right)_{2} \mathrm{InCl}_{2}\right\}(2)$, Tables S1 and S2: Summary of Structure Determination of $\left(\mathrm{pyNO}^{-}\right)_{2} \mathrm{GaCl}_{(1)}$ and $\left\{\left(\mathrm{pyNO}^{-}\right)_{2} \mathrm{In}\right\}\left\{\left(\mathrm{pyNO}^{-}\right)_{2} \mathrm{InCl}_{2}\right\}(2)$, Table S3: Optimized coordinates of $\left(\mathrm{pyNO}^{-}\right)_{2} \mathrm{GaCl}(\mathbf{1})$; Full Gaussian '09 Reference.

Author Contributions: C.R.G. conceived and designed the experiments; J.M.K. and A.J.W. performed the experiments; J.M.K. and P.R.R. performed the DFT calculations; B.C.M. and P.J.C. performed the X-ray diffraction and solved the crystal structure data; C.R.G., J.M.K., and A.J.W. analyzed the data; C.R.G. wrote the paper.

Acknowledgments: C.R.G. thanks Swarthmore College, the Research Corporation for Scientific Advancement (CCSA 23329), and the National Science Foundation (CHE-1664902) for financial support of this work. A.J.W. was supported through a James H. Scheuer Summer Internship in Environmental Studies. We thank the NSF (CHE-1337494) for funding toward the NMR spectrometer used in this work. We thank Bren E. Cole (University of Pennsylvania) for assistance collecting the X-ray diffraction data for complexes $\mathbf{1}$ and $\mathbf{2}$.

Conflicts of Interest: The authors declare no conflict of interest.

\section{References}

1. Caulton, K.G. Systematics and Future Projections Concerning Redox-Noninnocent Amide/Imine Ligands. Eur. J. Inorg. Chem. 2012, 2012, 435-443. [CrossRef]

2. Kaim, W. The Shrinking World of Innocent Ligands: Conventional and Non-Conventional Redox-Active Ligands. Eur. J. Inorg. Chem. 2012, 2012, 343-348. [CrossRef]

3. Luca, O.R.; Crabtree, R.H. Redox-Active Ligands in Catalysis. Chem. Soc. Rev. 2013, 42, 1440-1459. [CrossRef] [PubMed]

4. Lyaskovskyy, V.; de Bruin, B. Redox Non-Innocent Ligands: Versatile New Tools to Control Catalytic Reactions. ACS Catal. 2012, 2, 270-279. [CrossRef]

5. Cole, B.E.; Wolbach, J.P.; Dougherty, W.G., Jr.; Piro, N.A.; Kassel, W.S.; Graves, C.R. Synthesis and Characterization of Aluminum- $\alpha$-diimine Complexes over Multiple Redox States. Inorg. Chem. 2014, 53, 3899-3906. [CrossRef] [PubMed]

6. Koellner, C.A.; Piro, N.A.; Kassel, W.S.; Goldsmith, C.R.; Graves, C.R. Synthesis and Characterization of $\alpha$-Diimine Complexes of Group 13 Metals and Their Catalytic Activity toward the Epoxidation of Alkenes. Inorg. Chem. 2015, 54, 7139-7141. [CrossRef] [PubMed]

7. Poitras, A.M.; Bogart, J.A.; Cole, B.E.; Carroll, P.J.; Schelter, E.J.; Graves, C.R. Synthesis and Characterization of Aluminum Complexes of Redox-Active Pyridyl Nitroxide Ligands. Inorg. Chem. 2015, 54, 10901-10908. [CrossRef] [PubMed]

8. Herb, T.M.; Poitras, A.M.; Richardson, K.G.; Cole, B.E.; Bogart, J.A.; Carroll, P.J.; Schelter, E.J.; Graves, C.R. Synthesis and Characterization of Aluminum Nitroxide Complexes. Polyhedron 2016, 114, 194-199. [CrossRef]

9. Wilson, H.H.; Koellner, C.A.; Hannan, Z.M.; Endy, C.B.; Bezpalko, M.W.; Piro, N.A.; Kassel, W.S.; Sonntag, M.D.; Graves, C.R. Synthesis and Characterization of Neutral Ligand $\alpha$-Diimine Complexes of Aluminum with Tunable Redox Energetics. Inorg. Chem. 2018, in press. [CrossRef] [PubMed]

10. Bogart, J.A.; Lee, H.B.; Boreen, M.A.; Jun, M.; Schelter, E.J. Fine-Tuning the Oxidative Ability of Persistent Radicals: Electrochemical and Computational Studies of Substituted 2-Pyridylhydroxylamines. J. Org. Chem. 2013, 78, 6344-6349. [CrossRef] [PubMed]

11. Murakami, R.; Ishida, T.; Yoshii, S.; Nojiri, H. Single-molecule magnet $\left[\mathrm{Tb}(\mathrm{hfac})_{3}(2 \mathrm{pyNO})\right](2 \mathrm{pyNO}=$ t-butyl 2-pyridyl nitroxide) with a relatively high barrier of magnetization reversal. Dalton Trans. 2013, 42, 13968-13973. [CrossRef] [PubMed]

12. Bogart, J.A.; Lewis, A.J.; Medling, S.A.; Piro, N.A.; Carroll, P.J.; Booth, C.H.; Schelter, E.J. Homoleptic Cerium(III) and Cerium(IV) Nitroxide Complexes: Significant Stabilization of the 4+ Oxidation State. Inorg. Chem. 2013, 52, 11600-11607. [CrossRef] [PubMed]

13. Bogart, J.A.; Lewis, A.J.; Boreen, M.A.; Lee, H.B.; Medling, S.A.; Carroll, P.J.; Booth, C.H.; Schelter, E.J. A Ligand Field Series for the 4f-Block from Experimental and DFT Computed Ce(IV/III) Electrochemical Potentials. Inorg. Chem. 2015, 54, 2830-2837. [CrossRef] [PubMed] 
14. McSkimming, A.; Su, J.; Cheisson, T.; Gau, M.R.; Carroll, P.J.; Batista, E.R.; Yang, P.; Schelter, E.J. Coordination Chemistry of a Strongly-Donating Hydroxylamine with Early Actinides: An Investigation of Redox Properties and Electronic Structure. Inorg. Chem. 2018, 57, 4387-4394. [CrossRef] [PubMed]

15. Ishida, T.; Murakami, R.; Kanetomo, T.; Nojiri, H. Magnetic Study on Radical-Gadolinium(III) Complexes. Relationship Between the Exchange Coupling and Coordination Structure. Polyhedron 2013, 66, 183-187. [CrossRef]

16. Okazawa, A.; Nogami, T.; Ishida, T. tert-Butyl 2-Pyridyl Nitroxide Available as a Paramagnetic Chelate Ligand for Strongly Exchange-Coupled Metal-Radical Compounds. Chem. Mater. 2007, 19, 2733-2735. [CrossRef]

17. Okazawa, A.; Nogami, T.; Ishida, T. Strong Intramolecular Ferromagnetic Couplings in Nickel(II) and Copper(II) Complexes Chelated with tert-Butyl 5-Methoxy-2-Pyridyl Nitroxide. Polyhedron 2009, 28, 1917-1921. [CrossRef]

18. Okazawa, A.; Hashizume, D.; Ishida, T. Ferro- and Antiferromagnetic Coupling Switch Accompanied by Twist Deformation around the Copper(II) and Nitroxide Coordination Bond. J. Am. Chem. Soc. 2010, 132, 11516-11524. [CrossRef] [PubMed]

19. Myers, T.W.; Holmes, A.L.; Berben, L.A. Redox Routes to Substitution of Aluminum(III): Synthesis and Characterization of $\left(\mathrm{IP}^{-}\right)_{2} \mathrm{AlX}\left(\mathrm{IP}=\alpha\right.$-iminopyridine, $\mathrm{X}=\mathrm{Cl}, \mathrm{Me}, \mathrm{SMe}, \mathrm{S}_{2} \mathrm{CNMe}_{2}, \mathrm{C} \equiv \mathrm{CPh}, \mathrm{N}_{3}, \mathrm{SPh}, \mathrm{NHPh}$ ). Inorg. Chem. 2012, 51, 8997-9004. [CrossRef] [PubMed]

20. Myers, T.W.; Berben, L.A. Countercations Direct One- or Two-Electron Oxidation of an Al(III) Complex and Al(III)-oxo Intermediates Activate C-H Bonds. J. Am. Chem. Soc. 2011, 133, 11865-11867. [CrossRef] [PubMed]

21. Cates, C.D.; Myers, T.W.; Berben, L.A. (IP $)_{2}$ Ga ${ }^{\mathrm{III}}$ Complexes Facilitate Net Two-Electron Redox Transformations (IP = $\alpha$-Iminopyridine). Inorg. Chem. 2012, 51, 11891-11897. [CrossRef] [PubMed]

22. Addison, A.W.; Rao, T.N.; Reedijk, J.; Van Rijn, J.; Verschoor, G.C. Synthesis, Structure, and Spectroscopic Properties of Copper(II) Compounds Containing Nitrogen-Sulfur Donor Ligands: The Crystal and Molecular Structure of aqua[1,7-bis(N-methylbenzimidazol-2'-yl)-2,6-dithiaheptane]copper(II) perchlorate. J. Chem. Soc. Dalton Trans. 1984, 7, 1349-1356. [CrossRef]

23. Piskunov, A.V.; Ershova, I.V.; Bogomyakov, A.S.; Starikov, A.G.; Fukin, G.K.; Cherkasov, V.K. Indirect Magnetic Exchange between $o$-Iminosemiquinonate Ligands Controlled by Apical Substituent in Pentacoordinated Gallium(III). Inorg. Chem. 2015, 54, 6090-6099. [CrossRef] [PubMed]

24. Specklin, D.; Fliedel, C.; Hild, F.; Mameri, S.; Karmazin, L.; Bailly, C.; Dagorne, S. Mononuclear Salen-Gallium Complexes for iso-Selective Ring-Opening Polymerization (ROP) of rac-Lactide. Dalton Trans. 2017, 46, 12824-12834. [CrossRef] [PubMed]

25. Pugh, D.; Marchand, P.; Parkin, I.P.; Carmalt, C.J. Group $13 \beta$-ketoiminate Compounds: Gallium Hydride Derivatives as Molecular Precursors to Thin Films of $\mathrm{Ga}_{2} \mathrm{O}_{3}$. Inorg. Chem. 2012, 51, 6385-6395. [CrossRef] [PubMed]

26. Timoshkin, A.Y.; Bodensteiner, M.; Sevastianova, T.N.; Lisovenko, A.S.; Davydova, E.I.; Scheer, M.; Grassl, C.; Butlak, A.V. Do Solid-State Structures Reflect Lewis Acidity Trends of Heavier Group 13 Trihalides? Experimental and Theoretical Case Study. Inorg. Chem. 2012, 51, 11602-11611. [CrossRef] [PubMed]

27. Nogai, S.; Schriewer, A.; Schmidbaur, H. Reactions of trichlorogermane $\mathrm{HGeCl}_{3}$ and Dichlorogallane $\mathrm{HGaCl}_{2}$ with Pyridine Donors. Dalton Trans. 2003, 16, 3165-3171. [CrossRef]

28. Mitzel, N.W.; Lustig, C.; Woski, M. Different Modes of Aggregation in Organoaluminum and -gallium Hydroxylamides. Dalton Trans. 2004, 397-401. [CrossRef] [PubMed]

29. Jones, C.; Rose, R.P. Synthesis and Characterisation of Tetramethylpiperidinyloxide (TEMPO) complexes of Group 13 Metal Hydrides. New J. Chem. 2007, 31, 1484-1487. [CrossRef]

30. Boesing, P.; Willner, A.; Pape, T.; Hepp, A.; Mitzel, N.W. Structural Diversity in Bishydroxylamine Complexes of Ggallium. Dalton Trans. 2008, 19, 2549-2556. [CrossRef] [PubMed]

31. Lustig, C.; Mitzel, N.W. The Highly Flexible Bis(hydroxylamine) Ligand $[\mathrm{ON}(\mathrm{Me})]_{2} \mathrm{CH}_{2}{ }^{2-}$ and its Different Behavior in the Chemistry of Aluminum and Gallium. Angew. Chem. Int. Ed. 2001, 40, 4390-4392. [CrossRef]

32. Cotton, F.A.; Wilkinson, G.; Murillo, C.A.; Bochmann, M. Advanced Inorganic Chemistry, 6th ed.; John Wiley \& Sons, Inc.: New York, NY, USA, 1999; p. 1355.

33. Ogawa, A.; Fujimoto, H. Lewis Acidity of Gallium Halides. Inorg. Chem. 2002, 41, 4888-4894. [CrossRef] [PubMed] 
34. Thomson, R.K.; Scott, B.L.; Morris, D.E.; Kiplinger, J.L. Synthesis, Structure, Spectroscopy and Redox Energetics of a Series of Uranium(IV) Mixed-Ligand Metallocene Complexes. C. R. Chim. 2010, 13, 790-802. [CrossRef]

35. APEX II, v. 2012.10-0 or v. 2013.4-1; Bruker AXS: Madison, WI, USA, 2012.

36. Bruker APEX 3, v2016.1-0; Bruker AXS Inc.: Madison, WI, USA, 2015.

37. Bruker SAINT, v8.37a; Bruker AXS Inc.: Madison, WI, USA, 2012.

38. Sheldrick, G.M. SADABS; University of Göttingen: Göttingen, Germany, 2007.

39. Sheldrick, G.M. SHELXT-Integrated space-group and crystal-structure determination. Acta Crystallogr. Sect. A Found. Adv. 2015, A71, 3-8. [CrossRef] [PubMed]

40. Sheldrick, G.M. Crystal structure refinement with SHELXL. Acta Crystallogr. Sect. C Struct. Chem. 2015, C71, 3-8. [CrossRef] [PubMed]

41. Becke, A.D. Density-Functional Thermochemistry. III. The Role of Exact Exchange. J. Chem. Phys. 1993, 98, 5648-5652. [CrossRef]

42. Hay, P.J.; Wadt, W.R. Ab Initio Effective Core Potentials for Molecular Calculations. Potentials for K and Au Including the Outermost Core Orbitals. J. Chem. Phys. 1985, 82, 299-310. [CrossRef]

43. Hay, P.J.; Wadt, W.R. Ab Initio Effective Core Potentials for Molecular Calculations. Potentials for the Transition Metal Atoms Sc to Hg. J. Chem. Phys. 1985, 82, 270-283. [CrossRef]

44. Wadt, W.R.; Hay, P.J. Ab Initio Effective Core Potentials for Molecular Calculations. Potentials for Main Group Elements Na to Bi. J. Chem. Phys. 1985, 82, 284-298. [CrossRef]

45. Glendening, E.D.; Badenhoop, J.K.; Reed, A.E.; Carpenter, J.E.; Bohmann, J.A.; Morales, C.M.; Landis, C.R.; Weinhold, F. NBO 6.0; Theoretical Chemistry Institute, University of Wisconsin: Madison, WI, USA, 2013.

(C) 2018 by the authors. Licensee MDPI, Basel, Switzerland. This article is an open access article distributed under the terms and conditions of the Creative Commons Attribution (CC BY) license (http:/ / creativecommons.org/licenses/by/4.0/). 